\title{
Insight or Originality: A Spray in the River of Creative Thinking
}

\author{
Yan Wang ${ }^{*}$, Qinlong Hou ${ }^{2}$ \\ ${ }^{1}$ Ming Zheng Judicial Expertise Center, Jilin, China \\ ${ }^{2}$ The Clinical Immunology Research Center, Beihua University, Jilin, China \\ Email: *dair.yan@aliyun.com
}

How to cite this paper: Wang, Y. and Hou, Q.L. (2018) Insight or Originality: A Spray in the River of Creative Thinking. Open Access Library Journal, 5: e4847. https://doi.org/10.4236/oalib.1104847

Received: August 17, 2018

Accepted: September 8, 2018

Published: September 11, 2018

Copyright $\odot 2018$ by authors and Open Access Library Inc.

This work is licensed under the Creative Commons Attribution International License (CC BY 4.0).

http://creativecommons.org/licenses/by/4.0/

\begin{abstract}
One synthetic model of creativity was proposed, which tried to unify the dispute whether creativity was domain generality or specificity by supporting domain generality-specificity duality. The creative thinking process included convergent thinking, divergent thinking and insight (originality).
\end{abstract}

\section{Subject Areas}

Psychology

\section{Keywords}

Creativity, Convergent Thinking, Divergent Thinking, Insight, Originality

\section{Introduction}

Creativity refers to the ability of individuals to use known information to produce new and unique products with social value. It is the psychological quality necessary for successfully completing some creative activity. In our lives creativity has clear benefits for individuals and society in many aspects, such as: Music, painting, dance, mathematics, architecture and so on. However, is creativity a cognitive process of domain generality or specificity? This debate has been going on for decades and is supported by a number of empirical studies. Nowadays, it has become increasingly clear that creativity is not a single ability, but a combination of abilities and other aspects. Researchers gradually abandoned the "single dimensional creativity theory", and gradually constructed a system view of creativity, which led to the development of creativity research to "multi-dimensional orientation" and "polymerization model". Sternberg and Lubart's creative investment theory [1] argued that creative activities included intelli- 
gence, knowledge, thinking style, personality, motivation, and environment. Intelligence consisted of three elements: comprehensive ability, analytical ability and practical ability. The analytical and practical ability was more obvious field-general, and the comprehensive ability was field-special in a sense; knowledge was strong field-special; thinking style was relatively weak field-special; personality traits showed its particularity in different areas; environment also had different effects on different areas. The theory provides a unique perspective to study the particularity of the creative field. Simonton [2] pointed out that the domain-specific supporters didn't see creativity phenomenon at the abstract level. He believed that the blind variation and selective retention theory could eliminate the dispute. They also indicate that we can not simply think that creativity is field-special or field-general; on the contrary, this problem is more complicated.

\section{Divergent Thinking (DT) and Convergent Thinking (CT) with Chunk Theory}

The notion of divergent thinking (DT) was initiated by Guilford within his structure of intellect model, which describes the process that ideas are produced by searching for multiple possibilities as opposed to convergent thinking (CT) which defines the way to solve problem by looking for one correct solution [3] [4]. The DT explores the ability (or potential) to generate multiple solutions to an open-ended problem that does not have a right or wrong answer and to produce many ideas from a starting point. On the contrary, the CT reorganizes all kinds of information, which is characterized by the consistency of thinking in the same direction and the orderliness, conciseness, logic and regularity of thinking.

The DT approach is likely the most frequently used among theory-based approaches of creativity. Webb et al. [5] investigated different influence of convergent thinking and divergent thinking to solving insight and non-insight problems. They found a surprisingly weak relationship between divergent thinking and insight problem solving; however, convergent thinking had a stronger relationship with problem solving. As a conclusion, convergent thinking will also promote problem solving. Usually DT and CT both are used among human's creative activity.

Divergent thinking (DT) and convergent thinking (CT) are seemingly opposing yet interrelated processes. Just like two strands of power, DT breaks assumptions and rules, while CT keeps the boundaries and constraints. When Archimedes entered the bathtub to take a bath, he was still immersed in the examination of the crown's true gold. On the other hand, as he lay down in the bathtub, he found the overflowing water. It was because he entered the bathtub that the water overflowed. Suddenly, he realized that the overflowing water could measure the crown's volume. In this story, Archimedes' CT is one kind of constrains, and DT is one kind of needs which helped him to find the new connection be- 
tween the overflowing water and object's volume. In fact, very often new ideas are generated in response to constrains or needs that must be resolved.

Psychologists have long found that "chunking" information is the key to efficient cognitive ability, but it can also become a barrier to our thinking. Chunk decomposition refers to decompose familiar patterns into their component elements so that they can be regrouped in a meaningful manner. It is a creative process that can lead into insight [6].

Building on these ideas, we put out one idea about chunk recombination (see Figure 1) in creative thinking process. In normal state, chunk A (question) and chunk B (knowledge) both are in one balanced state under two strands of power (DT and CT). DT help chunk keep relationship with other chunks, and CT keep chunk in one completed state. When people find new contact between chunk A (question) and chunk B (knowledge) under power of DT, their new relationship will setup, and begin to chunk recombination (CT), and finally reach to one new chunk C (DT and CT), which in one new balanced state. The whole process mostly happened in a moment and suddenly.

\section{Originality and Divergent Thinking (DT) with Creative Insight}

By examining several characteristics of the products of the task, the DT approach permits the exploration of creative processes. Typically, DT tasks are scored for fluency (number of relevant productions), flexibility (number of different categories of productions), originality (number of unusual productions), and elaboration (the degree of enrichment of productions).

Kleibeuker et al. [7] examined developmental trajectories of creative cognition across adolescence. The two older age groups (18/19 years and 25/30 years) outperformed the two younger age groups (12/13 years and 15/16 years) on insight tasks. The older age group (25/30 years) performed better than the two youngest age groups on verbal divergent thinking originality. No age-group differences were observed for the fluency and flexibility measure of verbal divergent thinking. Chavez-Eakle et al. [8] found fluency and flexibility strongly correlated with cerebral blood flow (CBF) in left inferior frontal gyrus. Originality correlated with CBF in left superior temporal gyrus (STG) and cerebellar tonsil. Jung-Beeman et al. [9] found a sudden high frequency $\gamma$ wave originated from the right superior temporal gyrus (STG) at 0.3 second before insight production by EEG. They concluded the right STG was associated with establishing a connection between the originally irrelevant information. To sum up, insight has similar developmental trajectories and brain activity as originality, which is different from divergent thinking (fluency and flexibility). Originality or insight is the third factor except for divergent thinking and convergent thinking, and plays a pivotal role in creative thinking process.

The thinking process (Figure 2) includes convergent thinking, divergent thinking and insight. Insight is like a spray in the river of creative thinking. The 


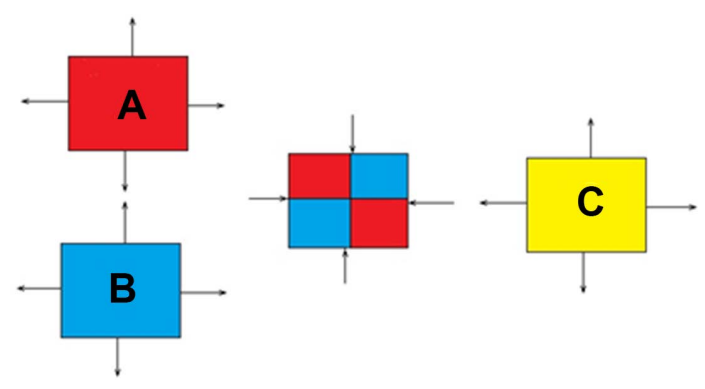

Figure 1. The chunk recombination.

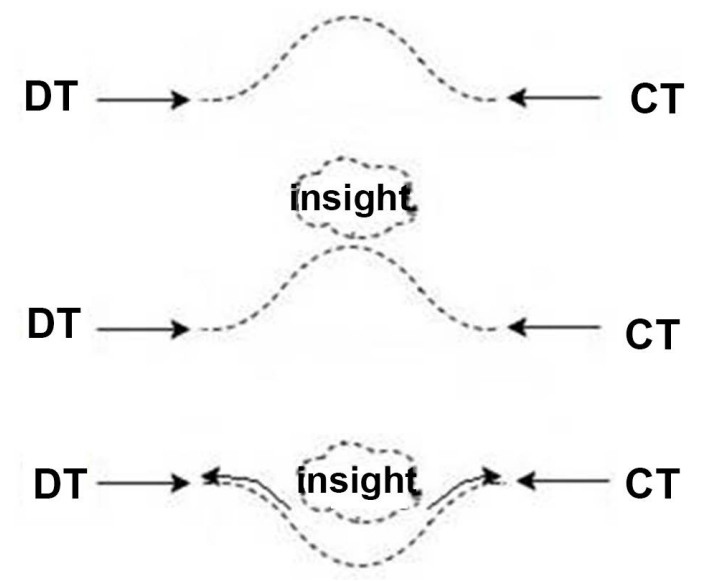

Figure 2. The creative thinking process.

interaction of convergent thinking's convergence effect and divergent thinking's diffusion effect, aroused a blossoming spray thinking (insight), which is the essence of human creative thinking. The spray either sublimate into a new idea (product), or fall down to stir up the ripples of the thinking river, and inspire new thinking waves. Estabrooks and Couch [10] revealed student's preference to characterize creative failure as a part of a larger process of inventing rather than to denote failure as an end point.

\section{One Synthetic Model of Creativity}

Based on the above, the author proposed one synthetic model of creativity (Figure 3). In this model, there are five main parts: individual reserve, thinking process, motivation, product and evaluation. The individual reserve includes personality (such as interests, hobbies, curiosity, perseverance and the physical conditions and so on), knowledge (such as mathematics, geography, biology, music and so on) and intelligence (such as observation, memory, comprehension, reasoning, expression and so on). The motivation comes from the surrounding environment, the educational or social requirements and individual need. The evaluation includes the community evaluation or self-evaluation on individual's creative products.

Just like the theory of wave-particle duality of light, the creativity is domain generality-specificity duality. For one thing, the thinking process part can 


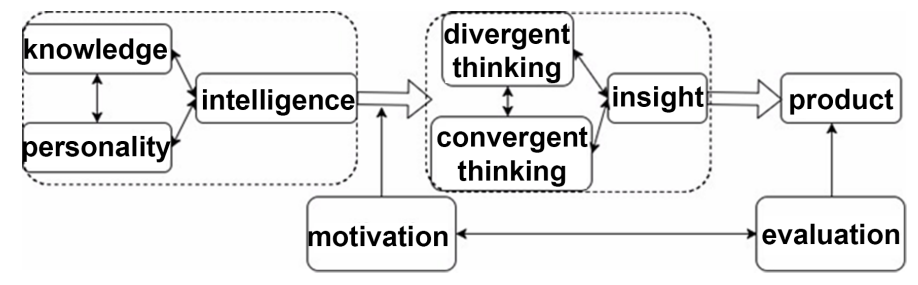

Figure 3. The synthetic model of creativity.

produce much divergent thinking and find one insight into one thing and keep on it. For another thing, each person has much different intelligence and knowledge, such as language, logic mathematics, space, nature, interpersonal, body-movement, music and self-awareness. One person may have more musical intelligence and he would create a new piece of music. In the process, his musical intelligence and knowledge plays a more important role, but his other intelligence and knowledge may also participate in. In a world, one's creative process (convergent thinking, divergent thinking, insight) is similar at the level of abstraction, however, the individual reserve used are different.

There are two questions we need to consider. The first is that the moment insight usually means to one new idea relative to individual at the abstract level. However, every insight would not equal to originality every time, that is not every "new" idea is creativity. Therefore, to some extent, originality is an index as insight in the synthetic model of creativity. In the future, we will continue to study the combination of creative thinking test and insight task. The second is that it is believed that insight is a necessary factor in our creative thinking process, except of convergent thinking and divergent thinking. Our creativity thinking process is one connection between freedom and control. Only conflict between them can produce beautiful "spray"-originality. The process also is one dynamitic process to be more deep and perfect during conflict and evaluation by oneself or community. Mayseless et al. [11] has proposed one dual mode of creativity based on neural unpinning of originality, which supported the synthetic model of creativity from neural mechanism. Therefore, we should put more attention to how the conflict between the convergent and divergent thinking produce insight, and how evaluation play a role.

\section{Conclusions}

One synthetic model of creativity was put forward which supported domain generality-specificity duality. The creative thinking process was discussed in detail from a new perspective. Originality or insight is the third factor except for divergent thinking and convergent thinking, and plays a pivotal role in creative thinking process. Just like two strands of power, DT breaks assumptions and rules, while CT keeps the boundaries and constraints. The conflict between them can produce beautiful "spray"-insight (originality).

However, this paper just presented one theory about creativity from another viewpoint. All theories need to be tested and verified by experimental data. Our 
future work will design relevant experiments to verify the theory and further improve the theory.

\section{Conflicts of Interest}

The authors declare no conflicts of interest regarding the publication of this paper.

\section{References}

[1] Sternberg, R.J. and Lubart, T.I. (1996) Investing in Creativity. American Psychologist, 51, 677-688. https://doi.org/10.1037/0003-066X.51.7.677

[2] Simonton, D.K. (2012) Teaching Creativity: Current Findings, Trends, and Controversies in the Psychology of Creativity. Teaching of Psychology, 39, 217-222. https://doi.org/10.1177/0098628312450444

[3] Guilford, J.P. (1950) Creativity. American Psychologist, 5, 444-454. https://doi.org/10.1037/h0063487

[4] Guilford, J.P. (1967) The Nature of Human Intelligence. McGraw-Hill.

[5] Webb, M.E., Little, D.R., Cropper, S.J. and Roze, K. (2017) The Contributions of Convergent Thinking, Divergent Thinking, and Schizotypy to Solving Insight and Non-Insight Problems. Thinking \& Reasoning, 23, 235-258. https://doi.org/10.1080/13546783.2017.1295105

[6] Knoblich, G. and Ohlsson, S. (1999) Constraint Relaxation and Chunk Decomposition in Insight Problem Solving. Journal of Experimental Psychology Learning Memory \& Cognition, 25, 1534-1555. https://doi.org/10.1037/0278-7393.25.6.1534

[7] Kleibeuker, S.W., De Dreu, C.K.W. and Crone, E.A. (2013) The Development of Creative Cognition across Adolescence: Distinct Trajectories for Insight and Divergent Thinking. Developmental Science, 16, 2-12. https://doi.org/10.1111/j.1467-7687.2012.01176.x

[8] Chavez-Eakle, R., Graff-Guerrero, A.R.J., Vaugier, V. and Cruz-Fuentes, C. (2007) Cerebral Blood Flow Associated with Creative Performance: A Comparative Study. NeuroImage, 38, 519-528. https://doi.org/10.1016/j.neuroimage.2007.07.059

[9] Jung-Beeman, M., Bowden, E.M., Haberman, J., Frymiare, J.L., Arambel-Liu, S., Greenblatt, R., Reber, P.J. and Kounios, J. (2004) Neural Activity When People Solve Verbal Problems with Insight. Plos Biology, 2, 500-510. https://doi.org/10.1371/journal.pbio.0020097

[10] Estabrooks, L.B. and Couch, S.R. (2018) Failure as an Active Agent in the Development of Creative and Inventive Mindsets. Thinking Skills \& Creativity. (Article in Press) https://doi.org/10.1016/j.tsc.2018.02.015

[11] Mayseless, N., Eran, A. and Shamay-Tsoory, S.G. (2015) Generating Original Ideas: The Neural Underpinnings of Originality. Neuroimage, 116, 232-239. https://doi.org/10.1016/j.neuroimage.2015.05.030 